\title{
DETERMINAÇÃO DA ESTRUTURA DE PROTEÍNAS USANDO RESTRIÇÕES DERIVADAS DE LIGAÇÃO CRUZADA EM ESPECTROMETRIA DE MASSAS: Comparação De Metodologias Computacionais
}

\section{Matheus M. dos Santos*, Leandro Martínez.}

\section{Resumo}

Sistemas biológicos trabalham como máquinas complexas e altamente coordenadas e, desde o surgimento da Biologia Estrutural, muitos mecanismos e estruturas biológicas foram elucidados devido a aplicação de métodos experimentais associados a metodologias computacionais que permitem compreender a dinâmica estrutural destes sistemas. Metodologias computacionais de modelagem molecular, que utilizam as distâncias experimentais como restrições para a determinação estrutural das macromoléculas,o método de determinação inferencial de estruturas (ISD, do inglês Inferential Structure Determination) tem se destacado como um método de alta resolução para determinação de estruturas terciárias e quaternárias de proteínas a partir de dados experimentais de espectroscopia de ressonância magnética nuclear (RMN) e de massas empregando ligações cruzadas (XL-MS). No presente trabalho foi possível observar que a alta resolução obtida provém da combinação de técnicas computacionais que empregam inferência bayesina, obtendo parâmetros e modelos de maior precisão, e também de simulated annealing, obtendo maiores espaços conformacionais, e por fim gerando estruturas de alta precisão.

\section{Palavras-chave:}

Proteínas; modelagem molecular; determinação estrutural.

\section{Introdução}

Proteínas desempenham diversas funções e apresentam estruturas complexas que influenciam diretamente suas funcionalidades ${ }^{1}$. A aplicação de métodos computacionais integrados a dados experimentais, vêm permitindo elucidar a estrutura de muito sistemas proteicos com resolução atômica ${ }^{1,2}$.

Uma metodologia utilizada na determinação de estruturas de proteínas é a Determinação Inferencial de Estrutura (ISD, do inglês Inferential Structure Determination), que trata a determinação estrutural como um problema de inferência bayesiana ${ }^{3}$, apresentando altas resolução e qualidade de estruturas. Deste modo, o presente trabalho visou compreender as técnicas empregadas por tal metodologia computacional e suas aplicações.

\section{Resultados e Discussão}

Os estudos da metodologia de Determinação Inferencial de Estrutura (ISD) utilizaram programa ARIA ${ }^{4}$ que ao tratar a determinação estrutural como um problema de inferência bayesiana ${ }^{4,5}$, calibra e obtém restrições de distância e, então, calculando a estrutura, empregando uma técnica de simulated annealing (SA), por meio de uma extensão do Crystallography \& NMR System ${ }^{5,6,7}$, de modo automatizado e iterativo. A combinação de tais técnicas na metodologia de ISD gera uma poderosa ferramenta de modelagem capaz de obter estruturas proteicas e espaços conformacionais de alta resolução e qualidade.

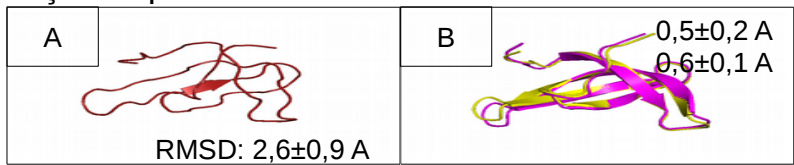

Figura 1: Estrutura genérica do domínio tudor gerada pelo ARIA em diferentes iterações: A) iteração 0; B) alinhamento iteração 8 (em amarelo) e estrutura refinada (em magenta), em solvente explícito.

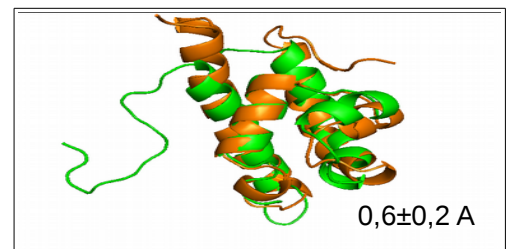

Figura 2: Alinhamento da estrutura do domínio HRDC da proteína da síndrome de Werner cristalográfica (em laranja) e determinada a partir da metodologia de ISD (em verde).

\section{Conclusão}

A metodologia de Determinação Inferencial de Estrutura (ISD) desenvolvida para elucidação de estruturas proteicas se mostra uma ferramenta poderosa de alta resolução, principalmente pela combinação do tratamento bayesiano do problema estrutural e do cálculo por meio de simulated annealing, que permite a análise de espaços conformacionais, obtenção de melhores taxas de convergência e eficiência computacional.

\section{Agradecimentos}

Esse trabalho foi financiado pelo Conselho Nacional de Desenvolvimento Científico e Tecnológico (CNPq). Agradecemos a todos os membros do Matínez Molecular Modeling Group $\left(M^{3} G\right)$, pelas discussões produtivas.

${ }^{1}$ LODISH, H. Molecular Cell Biology. 7th ed., W. H. Freeman, 2012. ${ }^{2}$ SALI, A.; GLAESER, R.; EARNEST, T.; BAUMEISTER, W. From words to literature in structural proteomics. Nature 422, p.216-225, 2003. ${ }^{3}$ RIEPING, Wolfgang; HABECK, Michael; NILGES, Michael. Inferential Structure Determination. Science 309, 303-306, 2005. ${ }^{4}$ RIEPING, W.; HABECK M.; BARDIAUX, B.; BERNARD, A.; MALLIAVIN, T.E.; NILGES, M. (2007) ARIA2: automated NOE assignment and data integration in NMR structure calculation Bioinformatics 23:381-382. ${ }^{5}$ NILGES, Michael; O’DONOGHUE, Seán I. Ambiguous NOEs and automated NOE assignment. Progress in Nuclear Magnetic Resonance Spectroscopy 32, p.107-139, 1998. ${ }^{6}$ A.T. Brunger, P.D. Adams, G.M. Clore, P.Gros, R.W. Grosse-Kunstleve, J.-S. Jiang, J. Kuszewski, N. Nilges, N.S. Pannu, R.J. Read, L.M. Rice, T. Simonson, G.L. Warren,Crystallography \& NMR System (CNS), A new software suite for macromolecular structure determination, Acta Cryst.D54, 905-921(1998). ${ }^{7}$ A.T. Brunger, Version 1.2 of the Crystallography and NMR System, Nature Protocols 2, 2728-2733 (2007). 